\title{
Adaption of Nonstandard Piping Components into Present Day Seismic Codes
}

\section{ASME Pressure Vessels and Piping Division Conference}

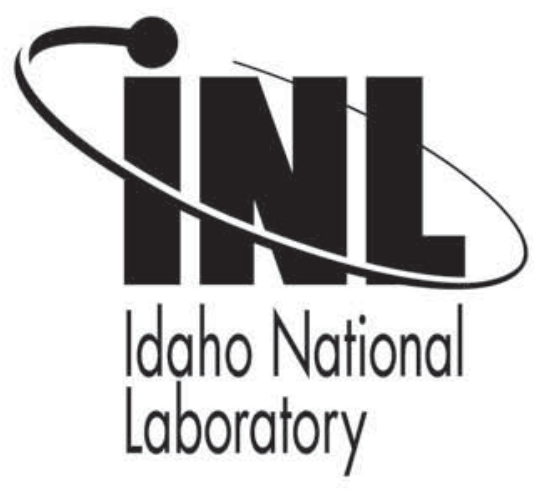

D. T. Clark

M. J. Russell

R. E. Spears

S. R. Jensen

July 2009

This is a preprint of a paper intended for publication in a journal or proceedings. Since changes may be made before publication, this preprint should not be cited or reproduced without permission of the author. This document was prepared as an account of work sponsored by an agency of the United States Government. Neither the United States Government nor any agency thereof, or any of their employees, makes any warranty, expressed or implied, or assumes any legal liability or responsibility for any third party's use, or the results of such use, of any information, apparatus, product or process disclosed in this report, or represents that its use by such third party would not infringe privately owned rights. The views expressed in this paper are not necessarily those of the United States Government or the sponsoring agency. 
PVP2009-77916

\section{ADAPTION OF NONSTANDARD PIPING COMPONENTS INTO PRESENT DAY SEISMIC CODES}

\author{
D. T. Clark, Lead Author \\ Senior Engineering Analyst \\ Structural \& Seismic Engineering Dept. \\ Idaho National Laboratory
}

\author{
R. E. Spears, Ph D, Co-Author \\ Senior Research Engineer \\ Structural \& Seismic Engineering Dept. \\ Idaho National Laboratory
}

\author{
M. J. Russell, Co-Author \\ Senior Structural Engineer \\ Structural \& Seismic Engineering Dept. \\ Idaho National Laboratory \\ S. R. Jensen, Co-Author \\ Senior Analysis Integrator \\ Structural \& Seismic Engineering Dept. \\ Idaho National Laboratory
}

\begin{abstract}
With spiraling energy demand and flat energy supply, there is a need to extend the life of older nuclear reactors. This sometimes requires that existing systems be evaluated to present day seismic codes. Older reactors built in the 1960s and early 1970s often used fabricated piping components that were code compliant during their initial construction time period, but are outside the standard parameters of present-day piping codes. There are several approaches available to the analyst in evaluating these nonstandard components to modern codes. The simplest approach is to use the flexibility factors and stress indices for similar standard components with the assumption that the nonstandard component's flexibility factors and stress indices will be very similar. This approach can require significant engineering judgment. A more rational approach available in Section III of the ASME Boiler and Pressure Vessel Code, which is the subject of this paper, involves calculation of flexibility factors using finite element analysis of the nonstandard component. Such analysis allows modeling of geometric and material nonlinearities. Flexibility factors based on these analyses are sensitive to the load magnitudes used in their calculation, load magnitudes that need to be consistent with those produced by the linear system analyses where the flexibility factors are applied. This can lead to iteration, since the magnitude of the loads produced by the linear system analysis depend on the magnitude of the flexibility factors. After the loading applied to the nonstandard component finite element model has been matched to loads produced by the associated linear system model, the component finite element
\end{abstract}

model can then be used to evaluate the performance of the component under the loads with the nonlinear analysis provisions of the Code, should the load levels lead to calculated stresses in excess of Allowable stresses. This paper details the application of component-level finite element modeling to account for geometric and material nonlinear component behavior in a linear elastic piping system model. Note that this technique can be applied to the analysis of ASME B31 piping systems.

\section{INTRODUCTION}

Piping systems in power plants, nuclear facilities, chemical plants are aging.

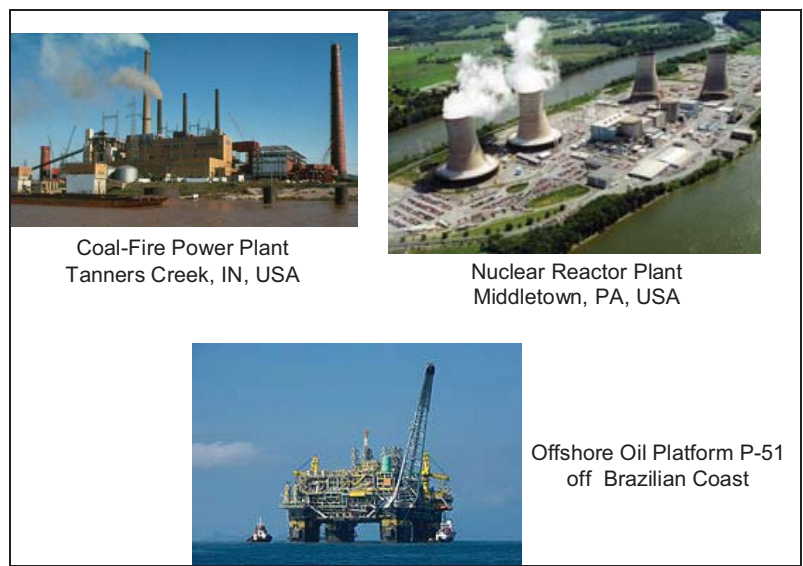

Figure 1 - Piping System Application Examples

1

The United States government retains, and by accepting the article for publication, the publisher acknowledges that the United States Government retains, a non-exclusive, paid-up, irrevocable, worldwide license to publish or reproduce the published form of this work, or allow others to do so, for United States Government purposes. 
With ever tightening economic constraints, there is a need to extend the life of older piping systems. This sometimes involves taking advantage of present day Code provisions in evaluating the older piping. Older plants built in the $1960 \mathrm{~s}$, and early 1970 s often used fabricated piping components that were compliant with their Codes of construction, but are outside the population of standard components defined in present-day piping codes $[1,2,3]$.

Present-day piping codes explicitly identify standard piping components, and by the process of elimination, nonstandard components. Most nonstandard components are easily identified in the same way. The presence of an unusual form or unusual welds indicating a nonstandard method of construction, or standard components which have been modified in the field, as shown in Figure 2.

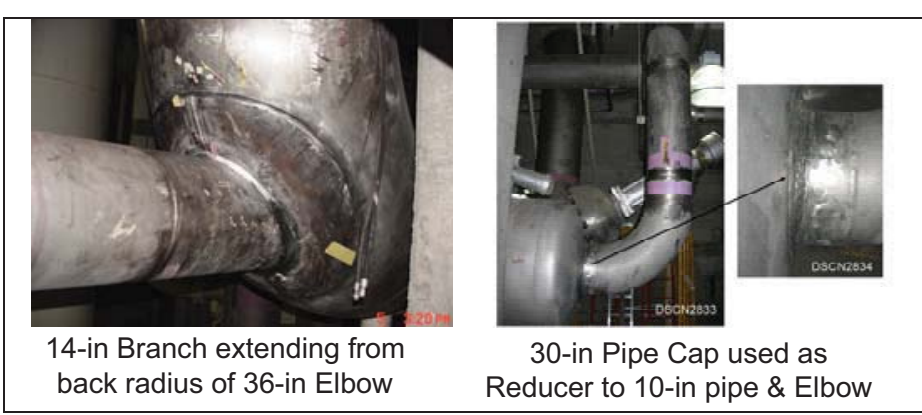

Figure 2 - Fabricated or Nonstandard Components

Within each piping code there is a list of ancillary standards that govern the manufacture of standard piping components. These include standard elbows, tees, branches, and so on. When performing piping analysis, care must be taken to determine if standard piping components truly are standard. If the piping component being analyzed does not meet the exact requirements of a standard component (for example, a branch to run diameter ratio limit is exceeded or a branch to run angle is less than allowed), then it must be classified as a nonstandard component and must be analyzed as such.

There are several approaches available to the analyst in evaluating these nonstandard components to modern codes. The simplest and potentially least accurate approach is to use the flexibility factors and stress indices for similar standard components, with the assumption that the nonstandard component's flexibility factor and stress indices will be very similar. This approach can rely strongly on judgment. Another approach, a spin-off the first approach, extracts component loads from a piping system analysis in which the component model is based on the similar standard component. The component loads are then applied to a finite element model of the nonstandard component to determine its acceptability. This method partially addresses the acceptability of the nonstandard component, but does not consider the effect of differences in flexibility between it and its representative standard component on the performance of the piping system.
A more accurate approach, which is the subject of this paper, involves iterative analyses of a detailed model of the nonstandard component along with analyses of a model of the associated piping system. Component loads from the system model are used to derive load consistent component flexibility factors. Changes in the flexibility factors are applied to the system model, which is rerun to generate new component loadings. This forms an iterative loop which is exercised until component loads and associated flexibility factors have converged to unchanging and consistent values. The component analysis, which may require geometric and possibly material nonlinearities, provides data that is used to define a secant stiffness to be applied to linear component in the system model. After convergence, the detailed component element model can then be used either to determine its stress indices for simplified evaluation using moments from the system model or it may be used in a detailed plastic analysis of the component. This approach to the analysis of nonstandard components can be applied to modern systems, as well as to aging systems.

\section{NONSTANDARD COMPONENT APPLICATION}

The analysis follows a standard breakout modeling approach, where two (or more) models are created, and each optimized for different purposes. Figure 3 is a flowchart of that process.

The system model represents the piping system to be evaluated. For computational efficiency, such a model will be too coarse to accurately detail the local flexibility of components, particularly when they are stressed beyond the range of their linear response. This model is optimized to efficiently generate component level response for the entire system.

A separate, detailed component model is created for the nonstandard component. This model will have high resolution of any features that will be subject to high stresses or which may add flexibility under high loads. The physical extent of the detailed model is made compatible with the corresponding component in the system model to allow accurate and efficient transfer of loads.

The system model is solved, and force and moment data for the nonstandard component is extracted and applied to the detailed component model. The component model is solved for these loads, yielding load-dependent flexibility factors. If these calculated flexibility factors are significantly different than those found in the system model, than an iteration step is required to correct the discrepancy. Once flexibility factors have converged, the component model may be used to calculate stress indices for the nonstandard component under the associated loads. The forces and moments from the system model, together with standard and nonstandard stress indices, are used to complete the elastic evaluation of the system per standard Code equations. For components found acceptable by such an evaluation, the analysis is complete. Components too highly loaded to be shown acceptable in this way can be shown

\section{2}

The United States government retains, and by accepting the article for publication, the publisher acknowledges that the United States Government retains, a non-exclusive, paid-up, irrevocable, worldwide license to publish or reproduce the published form of this work, or allow others to do so, for United States Government purposes. 
acceptable using any of several inelastic evaluation procedures with associated acceptance criteria provided in the Codes. These plastic analyses can make use of the existing detailed component models.

While it may be possible to combine the two models into a single system model with detailed components, such an approach is outside Code provisions.

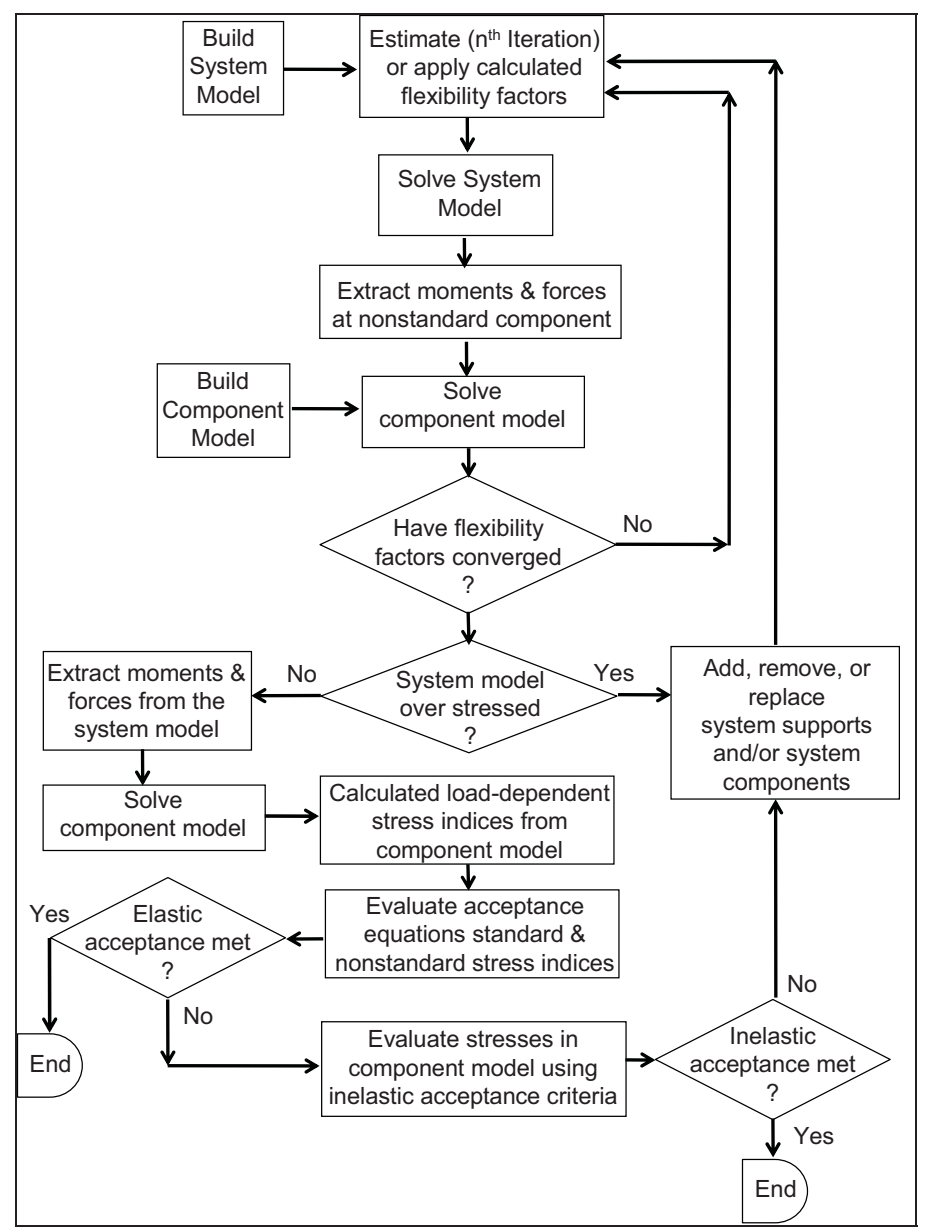

Figure 3 - Flowchart of nonstandard adaption process.

\section{NONSTANDARD COMPONENT FLEXIBILITY FACTOR \& STRESS INDICES DETERMINATION}

Application of nonstandard components within a linear piping system model is based on its flexibility factor, which are used to represent the nonstandard component's behavior within the piping system. These factors determine how loads are distributed throughout the piping system with the nonstandard component flexibility characteristics included. A second type of factor is the stress index, which is used to determine Code stresses for the component. Code Stresses are used to determine if components meets Code stress requirements. Both flexibility factors and stress indices must be determined for nonstandard components.

Two nonstandard component applications are used to demonstrate in this paper how flexibility factor and stress indices are determined. Both examples are pressurized piping systems that are used to keep a nuclear reactor cooled. The first nonstandard component application consists of a branch that does not meet Code requirements for run to branch pipe diameter ratio. The nonstandard Tee's (as the branch is called in this paper) flexibility factor determination is demonstrated. A second nonstandard component consists of a Branch component (called a Wye here) that does not meet standard component branch to run angle requirements. It's at 45 degrees from the run piping. The Wye's stress indices determination is shown.

Both nonstandard component applications (Tee and Wye) are found within the same piping system model (referred to as Model 1). Both are analyzed to the ASME Section III, Subsection NB piping provisions. Figure 4 shows piping Model 1 with the location of the two nonstandard components identified.

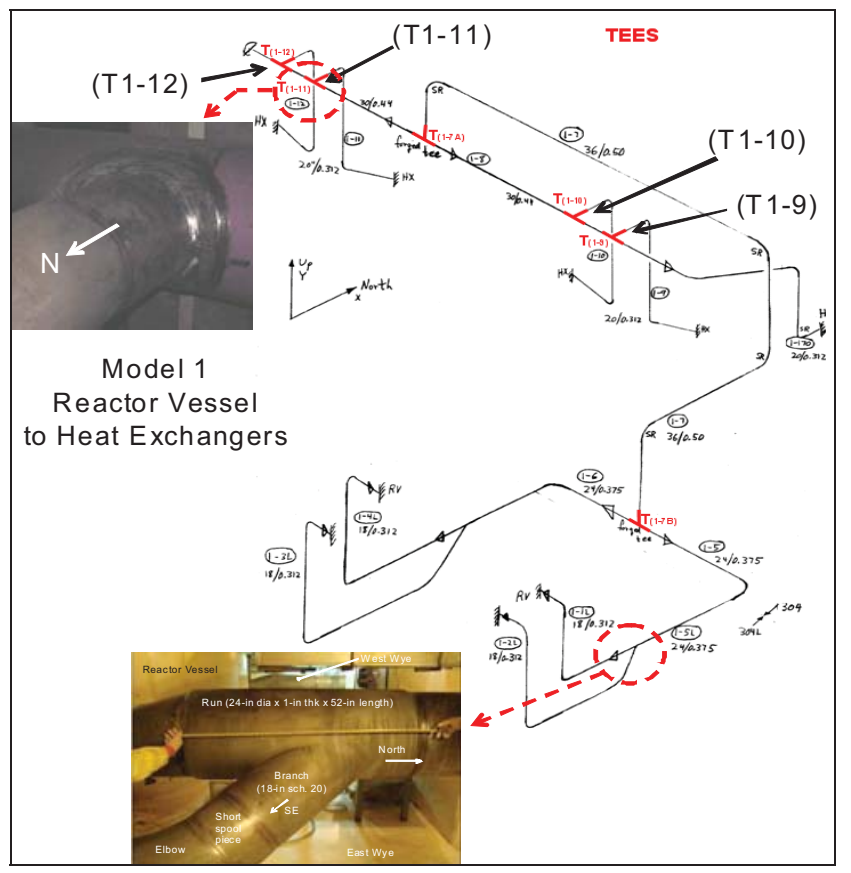

Figure 4 - Piping model 1 Nonstandard Components

\section{Nonstandard Tee Flexibility Factor Application}

Tee T1-11, shown in Figure 5, is used to demonstrate flexibility factor determination for nonstandard components. T1-11 was determined to be nonstandard because its diameter ratio (branch/run) exceeds that of a standard branch. Tee T1-11 is constructed of 304 stainless steel material with Design properties at $167^{\circ} \mathrm{F}$ and $272 \mathrm{psi}$. T1-11 features are similar to those of T1-9, T1-10, and T1-12, which are also located on line 1-8 (30-in x 0.438-in thick header run with a north horizontal branch (20-in x 0.312 -in thick pipe) and reinforced with 0.375 plating. The code definition for flexibility factor is shown following.

\section{3}

The United States government retains, and by accepting the article for publication, the publisher acknowledges that the United States Government retains, a non-exclusive, paid-up, irrevocable, worldwide license to publish or reproduce the published form of this work, or allow others to do so, for United States Government purposes. 
$k=\frac{\theta_{\mathrm{ab}}}{\theta_{\text {nom }}} \quad$ Flexibility Factor [3, Section NB-3682]

where k - Flexibility Factor $\theta_{\mathrm{ab}}$ - rotation of end "a" with repsect to end "b", due to a
moment load $\mathrm{M}$ in the direction of the moment $\mathrm{M}$

$\theta_{\text {nom }}$ - nominal rotation due to moment load M

Flexibility factor code equations are provided and used to determine the flexibility factor for standard components.

The first step for determining flexibility factor for the nonstandard tee is to create a T1-11 shell model and isolate a similar beam model from the piping system model, as shown in Figure 5.

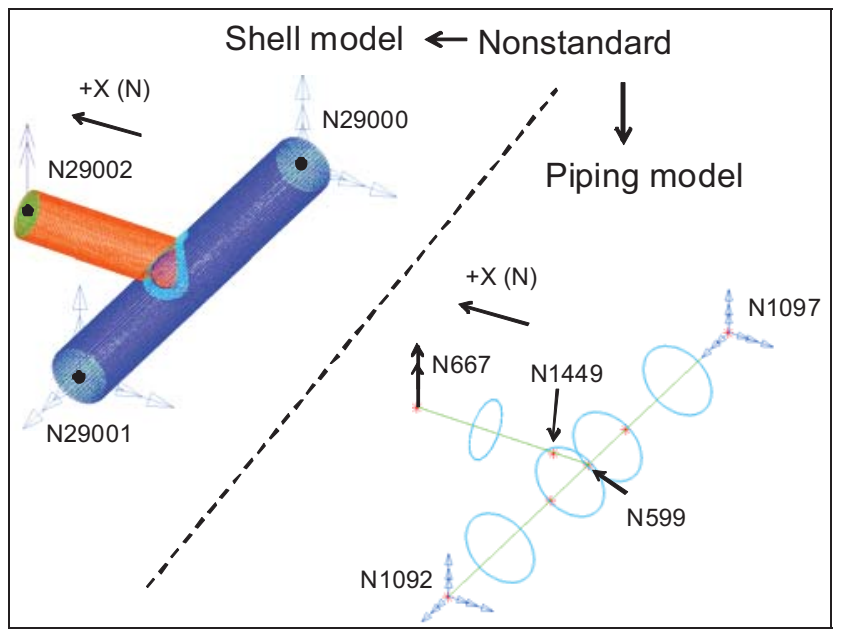

Figure 5 - T1-11 shell and piping models shown with same boundary conditions.

As shown in Figure 5, a shell model of nonstandard T1-11 is accurately portrayed and a beam model (extracted from the piping system model) representing T1-11, is also shown. Note that both models have the same boundary conditions placed on model nodes.

Combining Figure 5 with the defining equation for flexibility factor (previously shown) helps to understand how T1-11's flexibility factor is determined. The beam model in Figure 5 has already been solved and maximum moment reactions in the $\mathrm{X}, \mathrm{Y}$, and $\mathrm{Z}$ axis directions have already been obtained. For nonstandard components, the basic definition of " $\mathrm{k}$ " is based on angular deflections from the ratio of the shell model to that of the isolated piping model. $\theta_{\text {nom }}$ is associated with the isolated T1-11 piping beam model that places maximum $\mathrm{X}, \mathrm{Y}, \mathrm{Z}$ axis moments individually to the branch tip (N667) and solved independently to obtain three sets of angular deflections based on maximum coordinate moments. $\theta_{\mathrm{ab}}$ is associated with the T1-11 shell model, where angular deflections are retrieved in like manner as that of the isolated piping model. The flexibility factor or " $\mathrm{k}$ " is then determined. T1-11 k-values for the shell/piping axis models are compared in Figure 6.

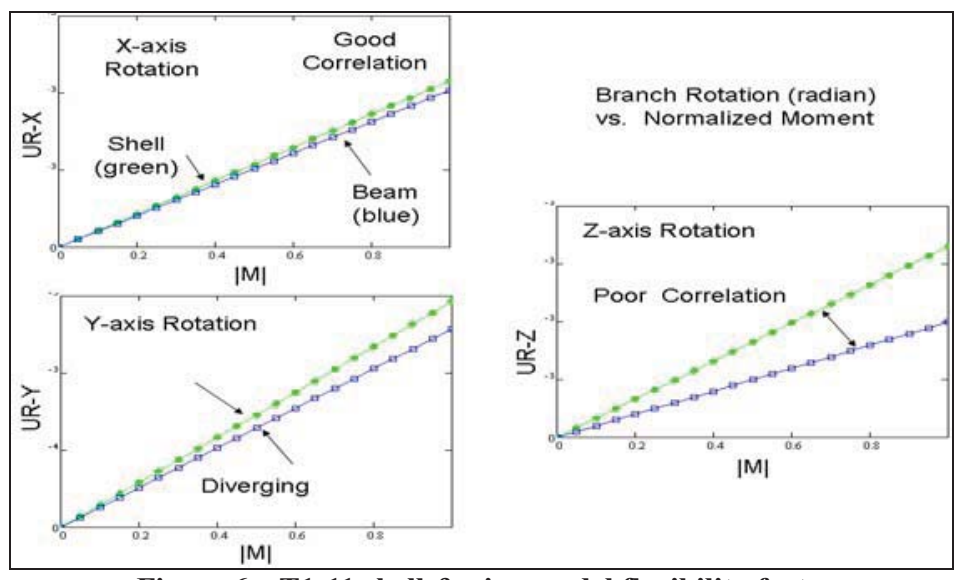

Figure 6 - T1-11 shell \& pipe model flexibility factor correlation in $\mathrm{X}, \mathrm{Y}, \& \mathrm{Z}$ axis directions.

As shown in Figure 6, flexibility factor correlation between the shell and beam models show good correlation about the $\mathrm{X}$-axis, but diverges for the $\mathrm{Y} \& \mathrm{Z}$ directions. The shell model reflects the correct flexibility factor for the T1-11 nonstandard component. There is a need to incorporate the shell model flexibility factor into the beam system model. How to do this is demonstrated for the T1-11 Z-axis rotation condition, which for this nonstandard component reflects the worst direction correlation. Figure 7 shows the shell and pipe model nodes \& corresponding directions.

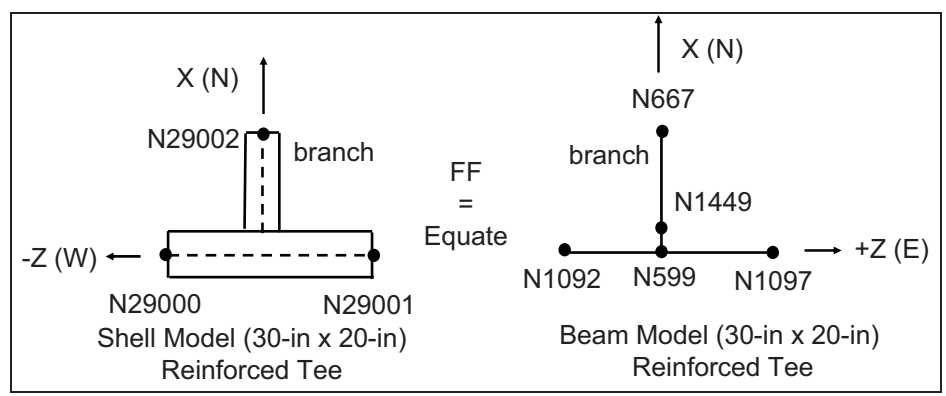

Figure 7 - Illustrates shell/pipe model nodes \& directions

In Figure 7, the beam model has five nodes to depict T111 , whereas the shell model has three nodes. The beam model uses a rigid element that connects at N1449 (surface of branch/run connection) and extends through to the run's centerline axis to N599. This rigid portion is referred to as the center segment. The shell model does not have a center segment, for this portion of T1-11 modeled around this volume. Therefore, obtaining a shell center segment is key to determining an appropriate flexibility factor to be applied to the system beam model that reflects the true T1-11 flexibility factor. Figure 8 shows angular deflections versus maximum normalized moment in the Z-direction.

4

The United States government retains, and by accepting the article for publication, the publisher acknowledges that the United States Government retains, a non-exclusive, paid-up, irrevocable, worldwide license to publish or reproduce the published form of this work, or allow others to do so, for United States Government purposes. 


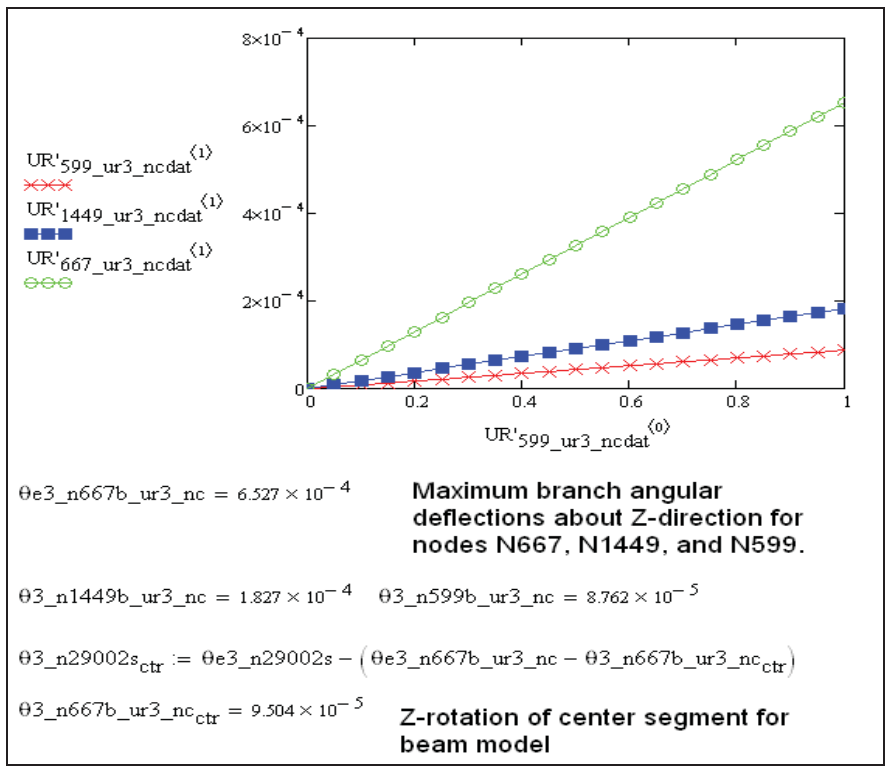

Figure 8 - Max. beam nodal deflections of T1-11 piping model.

Figure 8 is used to determine beam model center segment maximum deflection. This is used to determine the shell model's center segment by equating the two shell and beam models together. Following are equations that show the shell and beam models equated and used to determine the flexibility factor (about the Z-direction) that then is used to calculate the pipe branch moment of inertia to conform to the shell model's flexibility factor.

$$
\begin{aligned}
& \theta \mathrm{e} 3 \mathrm{n} 29002 \mathrm{~s}=3.303 \times 10^{-3} \quad \text { Maximum branch angular deflection about } \\
& \text { Z-direction for node 29002, of the shell model. } \\
& \theta 3 \_\mathrm{n} 29002 \mathrm{~s}_{\mathrm{ctr}}:=\theta \mathrm{e} 3 \mathrm{n} 29002 \mathrm{~s} \ldots \\
& +-\left[\theta \mathrm{e} 3 \_ \text {n667b_ur3_nc }-\theta 3 \_ \text {n667b_ur } 3 \_n c\right. \text { ctr) } \\
& \theta 3 \_n 29002 \mathrm{~s}_{\mathrm{ctr}}=2.745 \times 10^{-3} \text { Rotation center segment of shell model } \\
& \mathrm{k} 3 \mathrm{tl}_{-11}:=\frac{\theta 3 \_\mathrm{n} 29002 \mathrm{~s}_{\mathrm{ctr}}}{\theta 3 \mathrm{n} 667 \mathrm{~b} \mathrm{ur} 3 \mathrm{nc}_{\mathrm{ctr}}} \quad \mathrm{k} 3 \mathrm{tl}_{1} 11=28.885 \quad \begin{array}{l}
\mathrm{FF} \text { in global } 3 \\
\text { (Z-direction })
\end{array} \\
& I_{e}=\frac{I}{k} \quad \text { Net effective moment of inertia } \\
& \mathrm{J}_{\mathrm{e}}=\frac{\mathrm{J}}{\mathrm{k}} \quad \text { Net effective polar moment of inertia } \\
& \text { (Z-direction) }
\end{aligned}
$$

Directions:

Global $2(Y)$ Local $2(Y$ - strong axis bending)

Global 3 (Z) Local 3 ( $Z$ - weak axis bending)

Local branch net effective geometric properties:

$$
\mathrm{Iw}_{\mathrm{t} 1 \_11}:=\frac{\mathrm{I}_{\mathrm{branch}}}{\mathrm{k}_{\mathrm{t}} \_11} \quad \mathrm{Iw}_{\mathrm{t} 1 \_11}=32.379 \cdot \mathrm{in}^{4} \begin{aligned}
& \text { Net effective moment of inertia, } \\
& \text { weak axis }(\mathrm{Z}) \text { of branch }(\mathrm{T} 1-11)
\end{aligned}
$$

To check if the beam (piping) model now equates to the T1-11 shell model, the new weak axis moment of inertia in the Z-direction is applied to the piping model and solved again with the same maximum moment. Figure 9 shows the new beam and shell model flexibility factor results.
Global $1(X)$ Local $1(X$ - torsion)

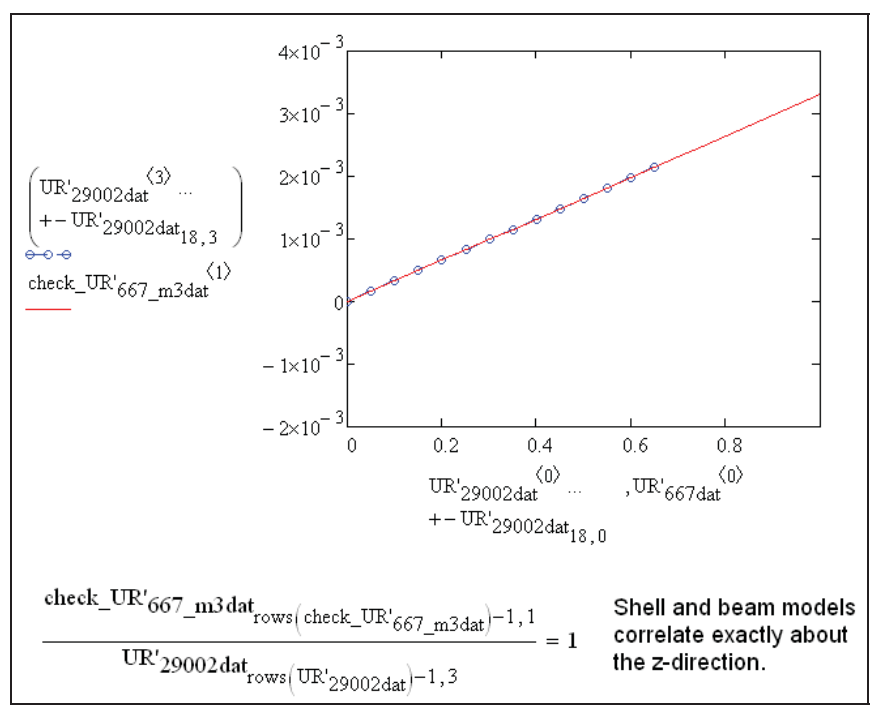

Figure 9 - Shell and beam model flexibility factor curves overlap, thus correlating exactly.

The same flexibility factor approach for the Z-direction should be performed for both the $\mathrm{X}$ and Y-directions, to force the pipe model to reflect the T1-11 nonstandard component shell model flexibility factor.

At this point, the piping system model is updated with correct T1-11 branch moment of inertia (correlating to the shell model's flexibility factor) and solved again. True moment reactions are extracted from the piping model at T1-11 and used to determine corresponding stress indices.

The flexibility factor for standard components is listed in a table or is determined by corresponding component equations.

\section{Nonstandard Branch Stress Indices Application}

As shown in Figure 4, a second nonstandard component consists of a Branch component (or Wye) that does not meet standard component branch to run angle requirements. A standard Branch component extends from its run at an angle ranging from $60^{\circ}-120^{\circ}$. This Branch component is nonstandard for it extends outward from the run at a $45^{\circ}$ angle. Unlike T111 , the Branch is constructed from 304L stainless steel with material properties at $167^{\circ} \mathrm{F}$ and maintains a constant internal gauge pressure 272 psi. The Branch segment is an 18 -in schedule 20 pipe and the run is a 24 -in diameter with a 1 -in wall, and has a 52-in length. The code definition for acceptable stress is shown following.

$$
\begin{aligned}
& \text { Equation } 9 \text { adapted for level D service limits } \\
& \begin{aligned}
&\text { (9) } \left.\mathrm{B}_{1} \cdot\left(\frac{\mathrm{P} \cdot \mathrm{D}_{\mathrm{O}}}{2 \cdot \mathrm{T}_{\mathrm{r}}}\right)+\mathrm{B}_{2 \mathrm{~b}} \cdot\left(\frac{\mathrm{M}_{\mathrm{b}}}{\mathrm{Z}_{\mathrm{b}}}\right)+\mathrm{B}_{2 \mathrm{r}} \cdot\left(\frac{\mathrm{M}_{\mathrm{r}}}{\overline{\mathrm{Z}_{\mathrm{r}}}}\right)\right]=\min \left(3^{*} \mathrm{Sm}, 2^{*} \mathrm{Sy}\right) \\
& \text { where } 3 \cdot \mathrm{Sm}_{167}=50.2 \cdot \mathrm{Sy}_{167}=44.52 \cdot \mathrm{ksi} \quad 2^{*} \text { Yield at } 167^{\circ} \mathrm{F} \text { governs } \\
&\text { (9) } \left.\mathrm{B}_{1} \cdot\left(\frac{\mathrm{P} \cdot \mathrm{D}_{\mathrm{o}}}{2 \cdot \mathrm{T}_{\mathrm{r}}}\right)+\mathrm{B}_{2 \mathrm{~b}} \cdot\left(\frac{\mathrm{M}_{\mathrm{b}}}{\mathrm{Z}_{\mathrm{b}}}\right)+\mathrm{B}_{2 \mathrm{r}} \cdot\left(\frac{\left.\mathrm{M}_{\mathrm{r}}\right)}{\mathrm{Z}_{\mathrm{r}}}\right)\right]<2 \cdot \mathrm{Sy}_{167}=44.52 \cdot \mathrm{ksi} \\
&
\end{aligned}
\end{aligned}
$$

\section{5}

The United States government retains, and by accepting the article for publication, the publisher acknowledges that the United States Government retains, a non-exclusive, paid-up, irrevocable, worldwide license to publish or reproduce the published form of this work, or allow others to do so, for United States Government purposes. 
Stress indices $\mathrm{B}_{1}, \mathrm{~B}_{2 \mathrm{~b}}$, and $\mathrm{B}_{2 \mathrm{r}}$ are needed to determine and then apply to code acceptance stress equation (9), which then determines nonstandard component acceptance. Approximate section modulus $Z_{\mathrm{b}}$ and $Z_{\mathrm{r}}$ are for the branch and run pipes for which equations are supplied by code, based on physical features of component geometry.

At this point, the Branch flexibility factor for each direction $(\mathrm{X}, \mathrm{Y}, \& \mathrm{Z})$ has already been determined and corresponding moment of inertias have been applied to the piping system and solved with new maximum moment reactions extracted from the piping system model at the Branch nonstandard component. The same shell mesh of the Branch developed for the flexibility factor determination is used for stress indices determination, as well.

As shown in Figure 10, the Branch shell mesh developed for the flexibility factor determination is used for stress indices determination. The piping system beam model is superimposed over the shell model, so that accordingly corresponding nodal piping moment reactions may be identified and applied to the shell model.

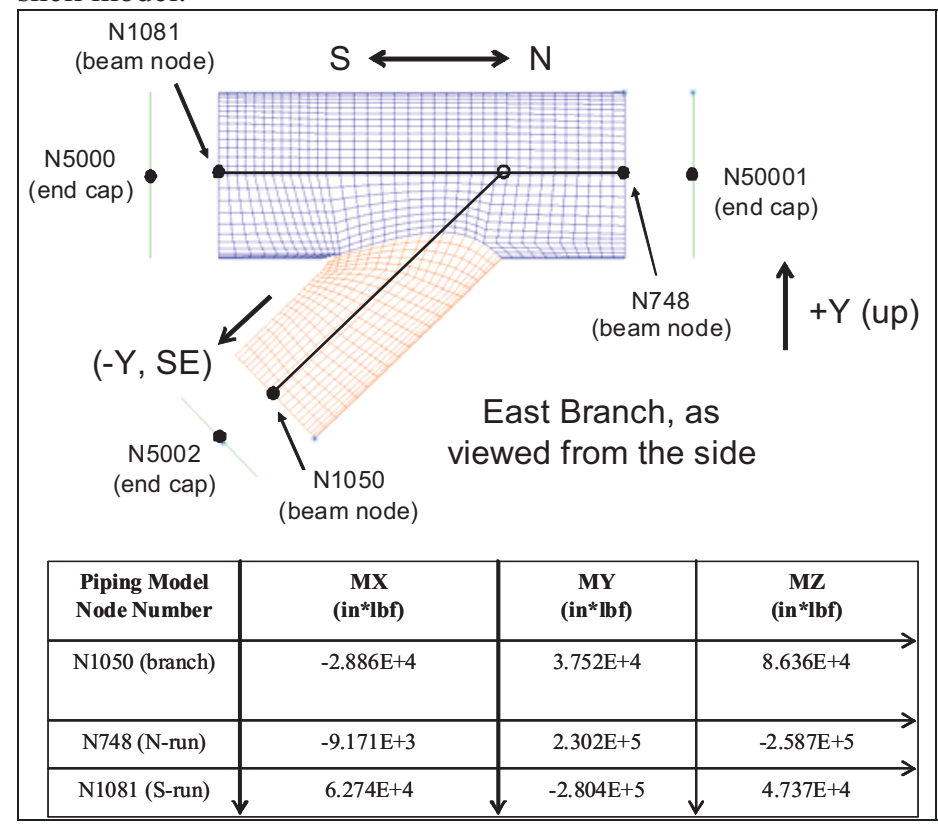

Figure 10 - Branch shell and beam models superimposed.

As shown in Figure 10, maximum moment magnitudes are shown, as extracted at the Branch nonstandard component from the beam model. These moments will be applied in the X, Y, Zdirections to the Branch shell model to obtain maximum tresca membrane stresses for four boundary condition cases, as shown in Figure 11.

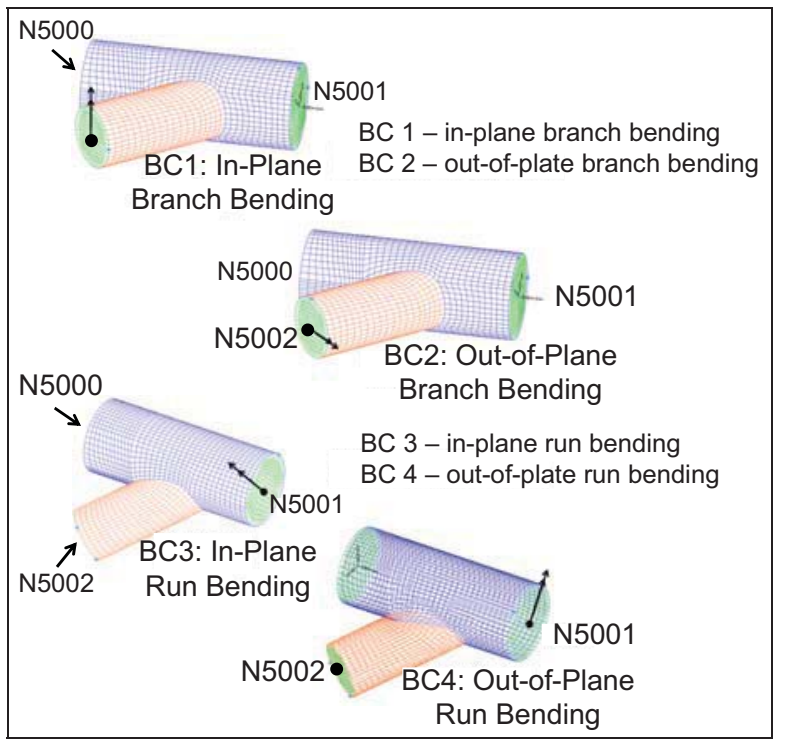

Figure 11 - Branch's four boundary condition cases shown.

Boundary condition cases $\mathrm{BC} 1$ and $\mathrm{BC} 2$ applies maximum piping system extracted moment (in corresponding direction) at N5002 to determine in-plane and out-of-plane bending Tresca membrane stresses. Likewise, boundary condition cases $\mathrm{BC} 3$ and BC4 apply beam model extracted moment at N50001 to determine corresponding in-plane and out-of-plane Run Tresca membrane stresses.

As shown earlier for service level $\mathrm{D}$ equation (9), $\mathrm{M}_{\mathrm{b}}$ and $\mathrm{M}_{\mathrm{r}}$ are resultant maximum moments applied at the branch (Mip, Mop) corresponding to moment in-plane and moment out-ofplane) and run ends. For the Branch nonstandard case, $\mathrm{M}_{\mathrm{b}}$ and $\mathrm{M}_{\mathrm{r}}$ are shown following.

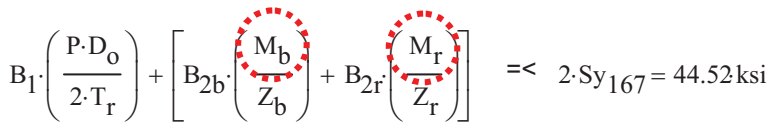

$$
\begin{aligned}
& (-0.394) \quad\left(6.818 \times 10^{4}\right) \\
& \text { MBip }_{5002}=7.187 \times 10^{4} \quad \text { MBop }_{5002}=-4.858 \times 10^{4} \\
& \left(6.733 \times 10^{4}\right) \quad\left(5.186 \times 10^{4}\right) \\
& \mathrm{NB}_{\text {ip }}:=\mathrm{MBip}_{5002} \quad \mathrm{NB}_{\text {ip }}=9.848 \times 10^{4} \quad \text { Branch in-plane \& } \\
& \mathrm{NB}_{\text {op }}:=\mathrm{MBop}_{5002} \quad \mathrm{NB}_{\mathrm{op}}=9.848 \times 10^{4} \text { out-of-plane } \\
& \text { are identical dues } \\
& \text { to symmetry. } \\
& \mathrm{M}_{\mathrm{ub}}:=\mathrm{NB}_{\mathrm{ip}} \cdot \mathrm{in} \cdot \mathrm{lbf} \quad \mathrm{M}_{\mathrm{ub}}=98.482 \text {.in.kip } \quad \text { Branch in-plane resultant } \\
& \operatorname{MnRip}_{5001}=\left(\begin{array}{c}
0 \\
=
\end{array}\right) \quad\left(\begin{array}{c}
0 \\
2.528 \times 10^{5}
\end{array}\right) \\
& \left(2.368 \times 10^{5}\right) \quad\left(-2.528 \times 10^{5}\right) \\
& \mathrm{NnR}_{\text {ip }}:=\mathrm{MnRip}_{5001} \quad \mathrm{NnR}_{\text {ip }}=3.464 \times 10^{5} \text { Run in-plane \& } \\
& \mathrm{NnR}_{\mathrm{op}}:=\text { MnRop }_{5001} \quad \mathrm{NnR}_{\mathrm{op}}=3.464 \times 10^{5} \begin{array}{l}
\text { out-of-plane } \\
\text { normal magnitudes } \\
\text { are identical, due }
\end{array} \\
& \text { to symmetry. } \\
& \mathrm{M}_{\mathrm{ur}}:=\mathrm{NnR}_{\mathrm{ip}} \cdot \mathrm{in} \cdot \mathrm{lbf} \quad \mathrm{M}_{\mathrm{ur}}=346.413 \cdot \mathrm{in} \cdot \mathrm{kip} \quad \begin{array}{l}
\text { Run in-plane resultant } \\
\text { moment at N5001 }
\end{array}
\end{aligned}
$$

6

The United States government retains, and by accepting the article for publication, the publisher acknowledges that the United States Government retains, a non-exclusive, paid-up, irrevocable, worldwide license to publish or reproduce the published form of this work, or allow others to do so, for United States Government purposes. 
Finite element branch membrane Tresca stress results are reflective of three load conditions (or steps). Step 1 produces the results for an internal pressure $(\mathrm{P}=272 \mathrm{psi})$ loading. Step 2 computes results for combined internal pressure and bending loading $(\mathrm{P}+\mathrm{Bi})$, where $\mathrm{Bi}$ represents branch section of wye. The last step (step 3) subtracts step $1(\mathrm{P})$ from step $2(\mathrm{P}+\mathrm{Bi})$ to obtain corresponding bending Tresca stress results (Bi). This is done to capture the added stiffness of internal pressure reflected into $\mathrm{Bi} \& \mathrm{Ri}$ (or Run bending) results. Maximum Tresca stresses (extracted from FE model results) of the inplane and out-of-plane moments are used to determine the branch stress indices $\left(\mathrm{B}_{2 \mathrm{~b}}\right)$ and run stress indices $\left(\mathrm{B}_{2 \mathrm{r}}\right)$.

$$
\begin{aligned}
& \sigma \mathrm{T}_{\mathrm{b}}:=(1.74158 \mathrm{E}+03) \cdot \mathrm{psi} \text { in-plane bending Maximum branch } \\
& \sigma \mathrm{T}_{\mathrm{b}}:=(2.25053 \mathrm{E}+03)^{\cdot p s i} \text { Out-of-plane bending tresca stress occurs for } \\
& \sigma_{\mathrm{ub}}:=\max \left(\sigma \mathrm{T}_{\mathrm{b}}\right) \quad \sigma_{\mathrm{ub}}=2.251 \cdot \mathrm{ksi} \\
& (5.03937 \mathrm{E}+03) \text { In-plane bending Maximum run tresca } \\
& \sigma \mathrm{T}_{\mathrm{r}}:=\left(\begin{array}{ll}
5.03937 \mathrm{E}+03 \\
9.95146 \mathrm{E}+03
\end{array}\right)^{\cdot p s i} \quad \begin{array}{l}
\text { In-plane bending } \\
\text { Out-of-plane bending }
\end{array} \quad \begin{array}{l}
\text { Maximum run tresca occurs for } \\
\text { stress }
\end{array} \\
& \sigma_{\text {ur }}:=\max \left(\sigma \mathrm{T}_{\mathrm{r}}\right) \quad \sigma_{\mathrm{ur}}=9.951 \cdot \mathrm{ksi} \\
& \sigma_{\text {up }}:=51.5868 \mathrm{E}+03 \cdot \mathrm{psi} \quad \begin{array}{l}
\text { Unlisted branch component tresca stress due } \\
\text { to internal pressure }
\end{array}
\end{aligned}
$$

With the Tresca stresses determined, the stress indices can be readily determined and applied to equation (9) to determine the nonstandard Branch Demand/Capacity acceptance.

$$
\begin{gathered}
\sigma_{\mathrm{ub}}=\mathrm{B}_{2 \mathrm{ub}} \cdot\left(\frac{\left|\mathrm{M}_{\mathrm{ub}}\right|}{\mathrm{Z}_{\mathrm{b}}}\right) \quad \begin{array}{l}
\text { SI determination for } \\
\text { branch component: }
\end{array} \\
\mathrm{B}_{2 \mathrm{ub}}:=\frac{\sigma_{\mathrm{ub}}}{\left(\frac{\mathrm{M}_{\mathrm{ub}}}{\mathrm{Z}_{\mathrm{b}}}\right)} \quad \mathrm{B}_{2 \mathrm{ub}}=1.752 \quad \begin{array}{l}
\text { Unlisted branch } \\
\text { member SI }
\end{array}
\end{gathered}
$$

Use same method to determine remaining SI.

$$
\begin{aligned}
& \mathrm{B}_{2 \mathrm{ur}}:=\frac{\sigma_{\mathrm{ur}}}{\left(\frac{\left|\mathrm{M}_{\mathrm{ur}}\right|}{\mathrm{Z}_{\mathrm{r}}}\right)} \quad \mathrm{B}_{2 \mathrm{ur}}=7.059 \quad \text { Run member SI } \\
& \mathrm{B}_{1 \mathrm{u}}:=\frac{\sigma_{\mathrm{up}}}{\left(\frac{\mathrm{P} \cdot \mathrm{Do}_{\text {run }}}{2 \cdot \mathrm{T} 24_{\mathrm{r}}}\right)} \quad \mathrm{B}_{1 \mathrm{u}}=15.805 \quad \begin{array}{l}
\text { System } \\
\text { pressure SI }
\end{array}
\end{aligned}
$$

$$
\begin{aligned}
& \text { For NC Wye: } \\
& \left.\mathrm{B}_{1} \cdot \frac{\left(\mathrm{P} \cdot \mathrm{D}_{\mathrm{o}}\right)}{\left(2 \cdot \mathrm{T}_{\mathrm{r}}\right.}\right)+\mathrm{B}_{2 \mathrm{~b}} \cdot\left(\frac{\mathrm{M}_{\mathrm{b}}}{\left(\mathrm{Z}_{\mathrm{b}}\right.}\right)+\mathrm{B}_{2 \mathrm{r}} \cdot\left(\frac{\left.\left.\mathrm{M}_{\mathrm{r}}\right)\right\rceil}{\left.\left(\mathrm{Z}_{\mathrm{r}}\right)\right\rfloor}=2 \cdot \mathrm{Sy}_{167}=44.52 \cdot \mathrm{ksi}\right. \\
& \frac{\mathrm{B}_{1 \mathrm{u}}\left(\frac{\left.\mathrm{P} \cdot \mathrm{Do}_{\mathrm{run}}\right)}{2 \cdot \mathrm{T}_{\mathrm{r}}}\right)+\left[\mathrm{B}_{2 \mathrm{ub}} \cdot\left(\frac{\left.\mathrm{M}_{\mathrm{ub}}\right)}{\mathrm{Z}_{\mathrm{b}}}\right)+\mathrm{B}_{2 \mathrm{ur}}\left(\frac{\left.\left.\mathrm{M}_{\mathrm{ur}}\right)\right\rceil}{\mathrm{Z}_{\mathrm{r}}}\right)\right\rfloor}{2 \cdot \mathrm{Sy}_{167}}=1.433 \begin{array}{l}
\text { Model } 1 \mathrm{NS} \text { Wye } \\
\text { unacceptable. }
\end{array} \\
& \frac{\mathrm{B}_{1 \mathrm{u}} \cdot\left(\frac{\left.\mathrm{P} \cdot \mathrm{Do}_{\text {run }}\right)}{2 \cdot \mathrm{T} 24_{\mathrm{r}}}\right)}{2 \cdot \mathrm{Sy}_{167}}=1.159 \text { Pressure strongly influences linear results. }
\end{aligned}
$$

The nonstandard Branch component (or Wye) is significantly over Demand/Capacity unity. As shown above, pressure dominates the linear results. Thus, a plastic analysis on the nonstandard Branch component is recommended to determine Branch acceptance.

\section{NONSTANDARD COMPONENT PLASTICITY}

To run the plastic analysis for the nonstandard component Wye component, displacement and rotation results versus time were gathered from the beam element model (shown in Figure 12). These results were gathered from the three nodes identified in Figure 12. The translational and rotational displacements for the nodes are shown in Figures 13 and 14. Figures 13 and 14 each have nine curves that include the three nodes and the three directions for each node. (The nine curves in Figure 12 appear as three curves. Each of the apparent three curves contains a curve from each of the three nodes in "Figure 12. The difference in the nodal displacements is not noticeable in the curve because the maximum relative displacement is less than 0.15 inches.)

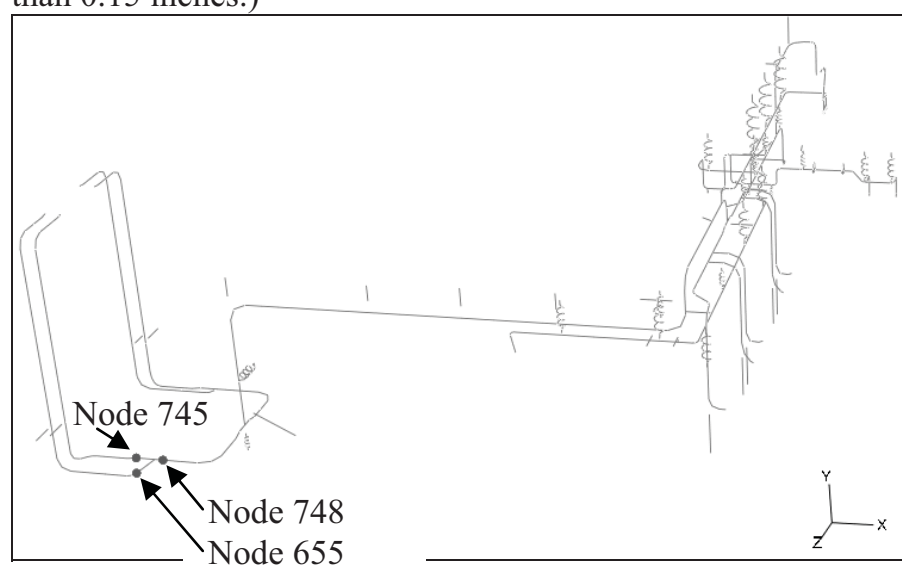

Figure 12 - Full beam element finite element model.

The United States government retains, and by accepting the article for publication, the publisher acknowledges that the United States Government retains, a non-exclusive, paid-up, irrevocable, worldwide license to publish or reproduce the published form of this work, or allow others to do so, for United States Government purposes. 


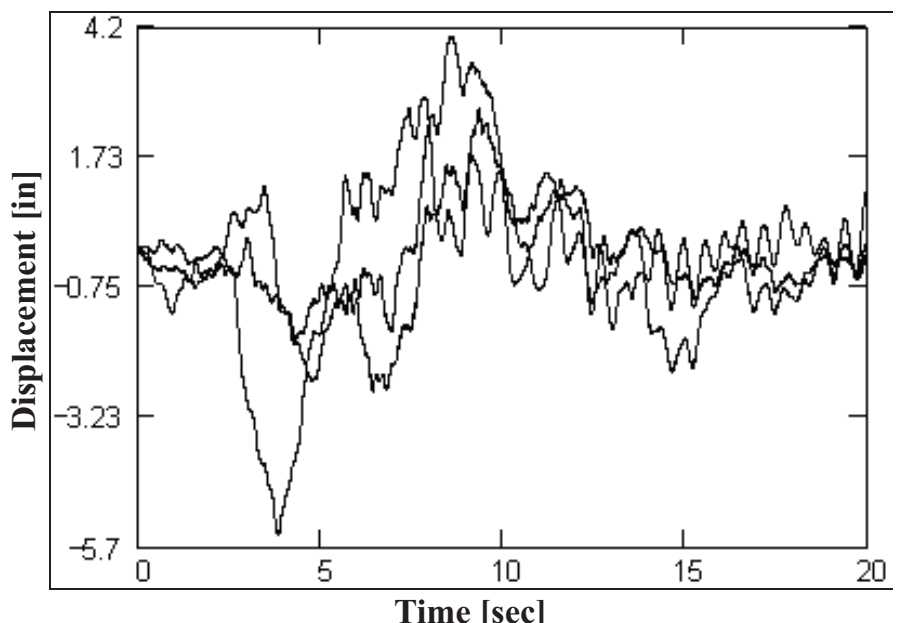

Figure 13 - Nodal translation for the three nodes.

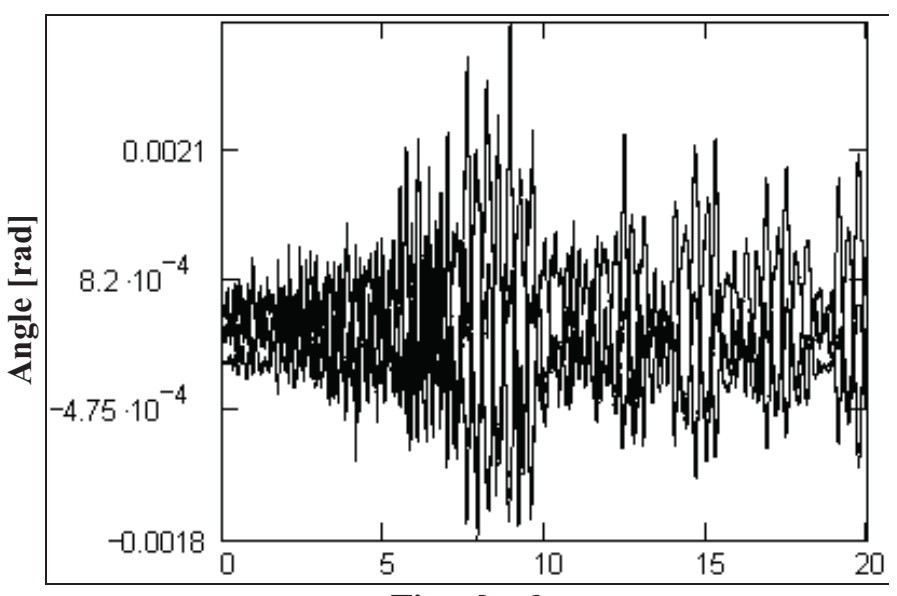

Time [sec]

Figure 14 - Nodal rotation for the three nodes.

Next, the region of the model within the identified nodes was regenerated with shell elements (as shown in Figure 15). This model was intended to model a region large enough to distance the boundary conditions from the location of highest plastic strain while not making the model any larger than necessary. The pipe portion of the model is continuum shells and the end caps are thin shells. Nodes for displacement input (not attached directly to any elements) were added in the correct spatial position on the model. These nodes were where the motion outputs from the nodes identified in Figure 12 were applied to the model. The nodes were then coupled with the nodes in the continuum shells at the cross section cuts where they occurred. This forced each cross section to translate and rotate with the corresponding node for displacement input. The design internal pressure was also added to the inside of the entire model.

The end caps were added for ease in evaluating the results. They contained the pressure. Therefore reaction forces read from the nodes for displacement input required no compensation for the pressure loads.
Material and geometric nonlinearity were evaluated in the shell finite element model. To define material nonlinearity, ASME Section II, Part D [5] was used to define engineering yield and tensile stress values and the Nuclear Systems Materials Handbook [6] was used to define elongation. A bilinear true stress versus true strain curve was then defined for an ABAQUS/Standard [7] finite element model run. The bilinear curve was linear from no stress to yield and then linear from yield to ultimate. (No material necking was allowed by the defined true stress versus true strain curve.)

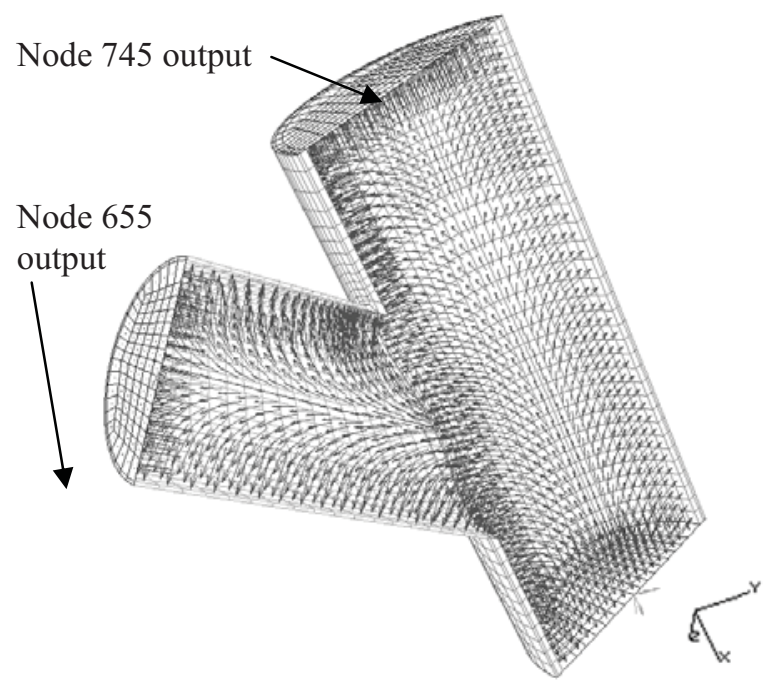

Figure 15 - Cut-away of the shell finite element model.

The results of this model run are shown in Figure 16. Figure 1 Node 748 output in of the highest strained region Node 748 output associated with the boundary conditions). (The end caps had higher strain in bending, but these strains have no relevance to any real strain.)

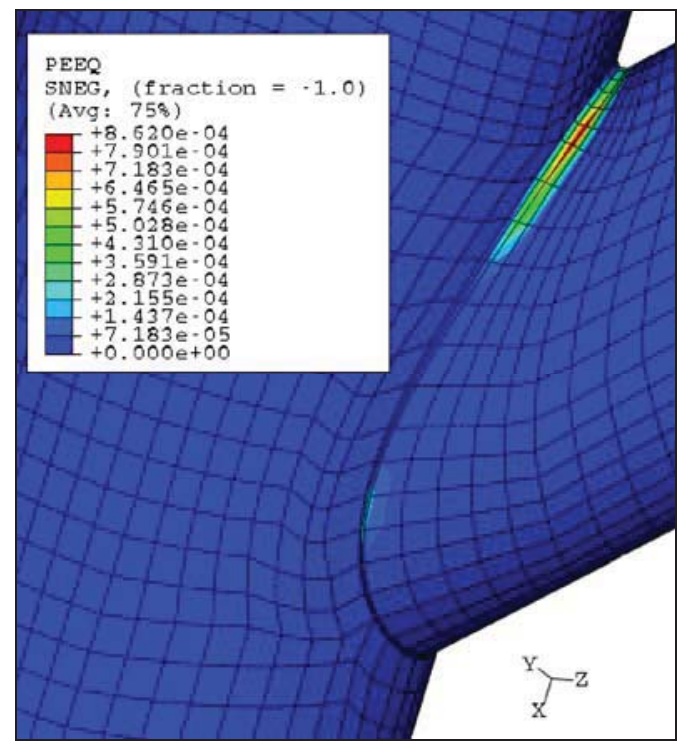

Figure 16 - Finite element model plastic equivalent strain. 8

The United States government retains, and by accepting the article for publication, the publisher acknowledges that the United States Government retains, a non-exclusive, paid-up, irrevocable, worldwide license to publish or reproduce the published form of this work, or allow others to do so, for United States Government purposes. 
Having a model run, the stress allowable was based on F1341.2 Plastic Analysis [8] which states that the stress allowable is the greater of $0.7 \mathrm{~S} u$ and $\mathrm{S} y+1 / 3(\mathrm{~S} u-\mathrm{S} y)$. It is desirable to present this allowable stress in a form easily compared to the plastic equivalent strain output (as shown in Figure 16). It is desirable because the plastic equivalent strain only grows and is tied to the stress. Therefore, observing the plastic equivalent strain at the end of the model run provides the knowledge necessary to establish the maximum stress that occurred during the model run. Considering the allowable stress, its conversion to true stress and true strain, and the bilinear true stress versus true strain curve used in the model, a maximum allowable plastic equivalent strain of $0.130 \mathrm{in} /$ in was established. This was much greater than the $0.00086 \mathrm{in} / \mathrm{in}$ evaluated in the model.

Acceptability was not ensured at this point because a check was needed to ensure that the (nonlinear) shell model Wye (in Figure 15) had a similar stiffness to that of the beam element Wye in the beam model (in Figure 12). Figure 17 shows the portion of the beam model equivalent to that of the shell model. Static bending moment versus angular displacement model runs for shell model (Figure 15) and the beam model (Figure 17) were then run as a stiffness comparison for the Wye. Considering that the branch had a much less significant cross section than the pipe run, the stiffness check was focused on the branch. The section properties for the branch element (identified in Figure 17) had adjusted moment of inertia section properties to create the bending moment versus angular displacement match shown in Figure 18. Figure 18 shows the angle versus moment plots for all three directions. These moments are representative of the maximum moments that occurred during the seismic event. The curves are based on the beam model and the data points are based on the shell model.

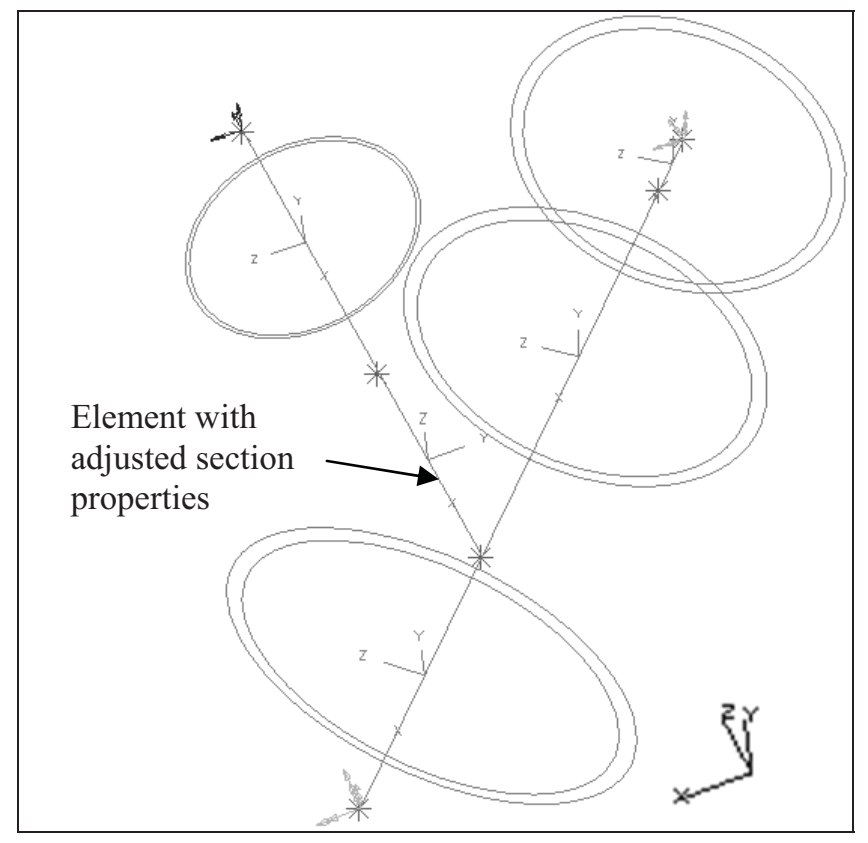

Figure 17 - Beam elements forming the Wye.

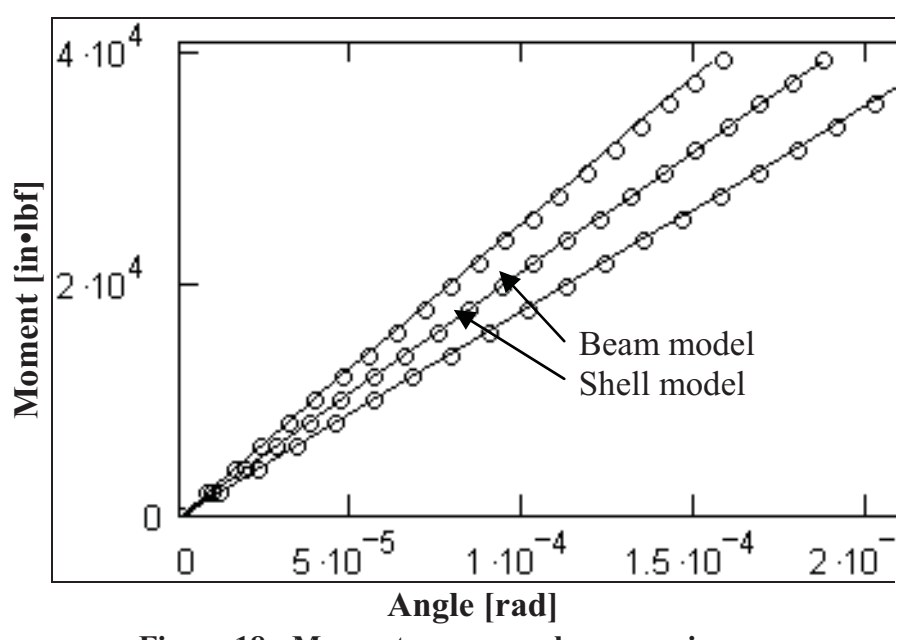

Figure 18 - Moment versus angle comparisons.

To achieve the match shown in Figure 18, an iterative process was performed. First, the seismic evaluation was performed on the beam model in Figure 12 with the element for adjusted section properties just having a regular beam section. Second, the Wye node output from the beam model was applied to the shell model. Third, maximum moments were pulled from the shell model. Fourth, static runs were performed on the shell model and beam elements forming the Wye. Fifth, the results were used to recalibrate the element with adjusted section properties and the process was started again.

Figure 18 shows good agreement between the beam element model and the corresponding shell element model. Given this match and the acceptable plastic equivalent strain during the seismic event, the Wye was considered acceptable for the seismic event.

\section{EXAMPLE PIPING SYSTEM RESULTS}

Changes in flexibility factor can have significant impact on the analysis results for the local piping system. Review of the results for the analyses discussed here established that the piping extending from the branch sides of the Tee and Wye had significant variations in Code moment (Square Root Sum of Squares) of the three moment directional components) resulting from changes in their associated flexibility factors. Final Code moments for the Tee branch piping varied from the initial moments through a range of -36 to 204 percent of the initial moments. The range for the Wye branch piping was from -72 to 114 of the initial moments. There are two sources for these variations. The first is the change in the dynamic characteristics of the piping resulting from the flexibility factor changes. The impact on the results depends on where the original piping system's natural frequencies fall on the seismic spectrum, and on how the flexibility factor changes these natural frequencies. Such changes can go in any direction. The second source is load redistribution due to the flexibility factor change. With this source, load is shed by a component 9

The United States government retains, and by accepting the article for publication, the publisher acknowledges that the United States Government retains, a non-exclusive, paid-up, irrevocable, worldwide license to publish or reproduce the published form of this work, or allow others to do so, for United States Government purposes. 
undergoing plastic deformation to adjacent components. For the particular case under discussion here, the predictable form of this second source was not apparent. Changes in piping system dynamic response governed.

\section{CONCLUSIONS}

This paper has presented a method to combine relatively coarse piping system models with detailed models of nonstandard components to produce a rational code evaluation of an existing piping system. This approach is more accurate than alternatives which approximate the response of nonstandard components, either by using related but different geometries, or by neglecting large displacements or other loadrelated nonlinearities which such components are particularly likely to exhibit.

The flexibility factors for nonstandard components may be a function of the load level. When they are, it is important to ensure that the flexibility factors used in the system model are compatible with the evaluated load levels. This ensures proper load distribution throughout the system model, and ensures that load shed from nonlinear response of nonstandard components is properly accounted for in adjacent system elements.

Incorporating plastic component behavior into a system model by creating an equivalent linear component has the usually beneficial effect of reducing the response frequency of the system model, which typically will reduce the applied seismic demand on the piping system. This procedure is an economical and technically sound solution, and is preferable to applying physical retrofits which will stiffen the system and ultimately increase the seismic demands both within the system and applied to supports and major components.

\section{ACKNOWLEDGMENTS}

Acknowledgment provided to A. L. Crawford for supplying piping figures for this paper.

This manuscript has been authored by Battelle Energy Alliance, LLC under Contract No. DE-AC07-05ID14517 with the U.S. Department of Energy. The United States Government retains and the publisher, by accepting the article for publication, acknowledges that the United States Government retains a nonexclusive, paid-up, irrevocable, world-wide license to publish or reproduce the published form of this manuscript, or allow others to do so, for United States Government purposes.

The work described in this paper was performed as part of the Advanced Test Reactor Life Extension Project.

\section{REFERENCES}

1. American Society of Mechanical Engineers (ASME) B31.1a-2008, "Power Piping."

2. American Society of Mechanical Engineers (ASME) B31.3-2008, "Process Piping."

3. American Society of Mechanical Engineers (ASME) Boiler \& Pressure Vessel Code BPVC, Section III,
Division 1 - Subsection NB, "Class 1 Components," ASME International, 2007 (with 2008 Addendum).

4. American Society of Mechanical Engineers (ASME) Boiler \& Pressure Vessel Code BPVC, Section III, Division 1 - Subsection N, Table N-1230-1. ASME International.

5. American Society of Mechanical Engineers (ASME) Boiler \& Pressure Vessel Code BPVC, Section II, Part D, "Materials," ASME International.

6. Nuclear Systems Materials Handbook, Volume II "Supporting Documentation for Design Data," Rev. 2, Dec. 1, 1977, INL Technical Library Special Selections, Set 113, Book 1, TID-26666.

7. ABAQUS Inc., ABAQUS Standard, Version 6.7-5, Rising Sun Mills, 166 Valley Street, Providence, RI, 02909-2499, Tel: +1-401-276-4400, email: support@,Abaqus.com.

8. American Society of Mechancical Engineers (ASME) Boiler \& Pressure Vessel Code BPVC, Section III, Division 1 - Appendices, Appendix F, "Rules for Evaluation of Service Loadings with Level D Service Limits," ASME International.

The United States government retains, and by accepting the article for publication, the publisher acknowledges that the United States Government retains, a non-exclusive, paid-up, irrevocable, worldwide license to publish or reproduce the published form of this work, or allow others to do so, for United States Government purposes. 